\title{
The Development and Growth of Tissues Derived from Cranial Neural Crest and Primitive Mesoderm Is Dependent on the Ligation Status of Retinoic Acid Receptor $\gamma$ : Evidence That Retinoic Acid Receptor $\gamma$ Functions to Maintain Stem/Progenitor Cells in the Absence of Retinoic Acid
}

\author{
Htoo Aung Wai, ${ }^{1}$ Koichi Kawakami, ${ }^{2}$ Hironori Wada, ${ }^{2}$ Ferenc Müller, ${ }^{3}$ Ann Beatrice Vernallis, \\ Geoffrey Brown, ${ }^{4}$ and William Eustace Basil Johnson ${ }^{1}$
}

Retinoic acid (RA) signaling is important to normal development. However, the function of the different RA receptors (RARs) - RAR $\alpha$, RAR $\beta$, and RAR $\gamma$-is as yet unclear. We have used wild-type and transgenic zebrafish to examine the role of RAR $\gamma$. Treatment of zebrafish embryos with an RAR $\gamma$-specific agonist reduced somite formation and axial length, which was associated with a loss of hoxb13a expression and less-clear alterations in hoxclla or myoD expression. Treatment with the RAR $\gamma$ agonist also disrupted formation of tissues arising from cranial neural crest, including cranial bones and anterior neural ganglia. There was a loss of Sox 9immunopositive neural crest stem/progenitor cells in the same anterior regions. Pectoral fin outgrowth was blocked by RAR $\gamma$ agonist treatment. However, there was no loss of Tbx-5-immunopositive lateral plate mesodermal stem/progenitor cells and the block was reversed by agonist washout or by cotreatment with an RAR $\gamma$ antagonist. Regeneration of the caudal fin was also blocked by RAR $\gamma$ agonist treatment, which was associated with a loss of canonical Wnt signaling. This regenerative response was restored by agonist washout or cotreatment with the RAR $\gamma$ antagonist. These findings suggest that RAR $\gamma$ plays an essential role in maintaining stem/ progenitor cells during embryonic development and tissue regeneration when the receptor is in its nonligated state.

\section{Introduction}

$\mathrm{R}$ ETINOIC ACID (RA) is a critical regulator of cell proliferation, cell differentiation, axis formation, and organogenesis in developing embryos [1,2]. RA can exist in three lipophilic forms, that is, all-trans RA, 9-cis RA, and 13-cis RA, all of which readily cross cell membranes to bind to a cytoplasmic carrier protein known as the cellular retinoic acid binding protein (CRABP) [3,4]. Once bound to CRABP, RA is translocated into the nucleus where it transfers to one of three types of the known RA receptors (RARs), termed RAR $\alpha$, RAR $\beta$, and RAR $\gamma$ [5]. These RARs form dimers with the retinoid X receptor (RXR) and RA ligation of the RAR:RXR complex upregulates expression of those genes that contain an RA response element (RARE). The mechanisms that affect such RA-driven alterations in gene expression include epigenetic changes and recruitment of coactivator proteins to the RAR:RXR of responsive genes [6]. However, RARs also function when not ligated to RA to repress gene expression. In this situation, nonligated RARs form an RAR-corepressorhistone deacetylase complex on RARE. This complex has been proposed to play a key role in the repression of gene expression in undifferentiated stem cells during early development [7]. Indeed, Koide et al. have shown that repression of gene expression is a key function of nonligated RAR during the regulated development of the head region in mice [8].

The specific roles of each of the different isoforms of RARs in regulating the response of stem/progenitor cells to RA during development remain largely unknown. Despite potential for functional redundancy, there is likely to be significant differences in RAR function because expression levels of RAR isoforms vary both temporally and spatially $[9,10]$. Geneknockout experiments of RARs in mice support differential function of RARs. For example, $R A R \alpha$-knockout mice exhibit no discernable phenotype [11] and $R A R \beta$-knockout mice have ocular defects and reduced body weight [12], while

${ }^{1}$ Life and Health Sciences, Aston University, Birmingham, United Kingdom.

${ }^{2}$ Division of Molecular and Developmental Biology, National Institute of Genetics, Mishima, Japan.

${ }^{3}$ School of Clinical and Experimental Medicine and ${ }^{4}$ School of Immunity and Infection, University of Birmingham, United Kingdom.

(c) Htoo Aung Wai et al. 2015; Published by Mary Ann Liebert, Inc. This Open Access article is distributed under the terms of the Creative Commons License Attribution-Non-Commercial Share Alike (<http://creativecommons.org/licenses/by-nc-sa/4.0/ $>$ ). 
knockout of $R A R \gamma$ results in several severe developmental defects, including growth deficiency, cartilage dysmorphogenesis, and vertebrate malformations [13]. However, as RARs can function both to repress as well as activate targeted gene expression through respective engagement by RAR of corepressor or coactivator proteins, the use of gene-knockout methods to determine the physiological role of RARs is problematic. For example, the deletion of RAR may result in release of corepressor proteins bound to the RAR when non-RA ligated and the activity of these released corepressors may in themselves produce developmental defects, at least in mammals [14]. Moreover, Williams et al. (2009) suggested that the ability of $\operatorname{RAR} \gamma$, in particular, to repress gene expression is required for normal skeletal development of long bones. Therefore, in order to fully understand the importance of RAR in regulating gene activity, there are advantages to the use of specific agonists and antagonists for each of the different RARs [14].

In zebrafish, there are two major RARs, RAR $\alpha$ and RAR $\gamma$ [10]. $R A R \gamma$ expression is restricted in early zebrafish embryos to mesodermal and neural crest stem/progenitor cells, in the head area, in the lateral plate mesoderm, and in the presomitic mesoderm of the tail bud $[9,10]$. Retinaldeyhyde dehydrogenase (RALDH), which is responsible for synthesizing RA, is not expressed within these areas $[16,17]$. Further, a transgenic reporter line indicating the presence of endogenous RA has shown that RA is not present in the tail bud, which is one of the locations for $R A R \gamma$ expression [18]. These nonoverlapping expression patterns of $R A R \gamma$ and $R A L D H$ suggest that RAR $\gamma$ does not function during development to activate RA-responsive genes. Instead, a lack of RAR $\gamma$-dependent transcriptional activity may be important and RAR $\gamma$ may play a key role in repressing gene expression in its nonligated state.

We hypothesized that if RAR $\gamma$ functions in its nonligated state to repress gene expression, then engaging an RAR $\gamma$-specific ligand will result in aberrant transcriptional activity of genes that by default should be switched "off." In other words, cells or tissues expressing $R A R \gamma$ that are affected by treatment with an $\operatorname{RAR} \gamma$ agonist may be those wherein $\operatorname{RAR} \gamma$ plays an important gene repressive activity. To investigate this possibility during embryonic development, this study has examined the effects of RAR $\gamma$-specific agonist treatments in zebrafish larvae [15]. Our findings have shown that treatment with an RAR $\gamma$ agonist has major deleterious consequences on the development of tissues that derive from neural crest and mesoderm, and also on caudal fin regeneration. The effects of the RAR $\gamma$ agonist treatments on the pectoral and caudal fin were reversed by washout of the agonist or cotreatment with an RAR $\gamma$-specific antagonist. We have also used transgenic reporter zebrafish lines to identify downstream pathways regulated by RAR $\gamma$ activity, which paradoxically showed decreased expression of some hox genes and canonical Wnt signaling. These findings provide evidence that $\operatorname{RAR} \gamma$ plays a critical role to maintain stem/progenitor cells during normal embryonic development and tissue regeneration, which depends on its ligation status.

\section{Materials and Methods}

\section{Zebrafish husbandry}

Stocks of the wild-type AB strain of zebrafish were maintained in the fish unit of the Biomedical Research facility in Aston University according to U.K. Home Office guidelines. The unit had a 14/10 h day/night cycle according to zebrafish husbandry guidelines [19]. Following breeding, zebrafish embryos were kept in an incubator at $28^{\circ} \mathrm{C}$ in petri dishes (SLS, Hessle, UK) in a $4 \mathrm{~mL}$ solution of Hank's solution (Molekula, Dorset, UK) or E3 fish media. Experiments using transgenic reporter fish were performed at the National Institute of Genetics (NIG) in Mishima, Japan, with husbandry according to NIG institutional guidelines [20]. Two transgenic hox gene reporter fish lines of the Gal4-UAS system were used, namely, the hoxclla and hoxb13a lines [21]. In these transgenic fish, the gene trap and enhancer trap constructs are integrated within hoxclla and hoxb13a genes, respectively. Therefore, Gal4FF expression is likely to recapitulate that of the endogenous genes [22]. The transgenic zebrafish reporter line HGn39D was used to visualize the lateral line [23]. The transgenic zebrafish reporter line Tcf:mini-p was used to visualize canonical Wnt signaling [24], which was kindly provided by Dr. Ishitani (Kyushu University). For Gal4-UAS breeding, either male or female adult zebrafish of the Gal4 line was crossed with UAS-GFP reporter zebrafish as pair-wise crossings in breeding tanks. The male and female zebrafish were separated using a barrier the evening before the actual day of breeding. The barrier was removed on the following morning to allow male and female mating and fertilized eggs were collected within $30-60 \mathrm{~min}$ of this using a strainer.

\section{$R A R \gamma$ reagents: preparation and treatment protocols}

The RAR $\gamma$-specific agonist (AGN205327) and antagonist (AGN205728) [15] were kept as $10 \mathrm{mM}$ stock solutions dissolved in 50\% dimethyl sulfoxide (DMSO) and 50\% methanol. These stocks were diluted with $100 \%$ DMSO to give a working stock solution at $100 \mu \mathrm{M}$ according to previously published studies [25]. These working stocks were then further diluted with Hank's solution or E3 media to the final doses used for the treatments of zebrafish embryos as given in "Results" section. A control solution of a 50\%:50\% DMSO: methanol-carrier-alone stock further diluted into 100\% DMSO and then into Hank's or embryo media was prepared using the exact dilutions that were used for the $\operatorname{RAR} \gamma$ reagents. Following treatment of zebrafish embryos by immersion in E3 media supplemented with the RAR $\gamma$ reagents or carrier alone at 4 hours postfertilization (hpf) (or at other times as indicated in "Results" section), the treated and control embryos were incubated at $28^{\circ} \mathrm{C}$ [19]. Zebrafish embryos were treated with the RAR $\gamma$ agonist at $4 \mathrm{hpf}$ because the agonist is not subjected to degradation and $R A R \gamma$ expression is detected at the $40 \%$ epiboly stage, which is around $5 \mathrm{hpf}$ [10].

\section{In situ hybridization and immunolocalization protocols}

In situ hybridization for myoD expression was performed according to previously published methods [26]. In brief, zebrafish embryos treated with the RAR $\gamma$ agonist (at $4 \mathrm{hpf}$ ) and control embryos were harvested at $22 \mathrm{hpf}$ and fixed in $4 \%$ paraformaldehyde (PFA) at $4^{\circ} \mathrm{C}$ overnight, before dehydrating in $100 \%$ methanol, also at $4^{\circ} \mathrm{C}$ overnight. The embryos were then serially rehydrated through decreasing 
alcohols (100\%-25\% methanol) finally to phosphatebuffered saline (PBS) alone. The rehydrated embryos were digested with proteinase K $(10 \mu \mathrm{g} / \mathrm{mL}$; Sigma, St. Louis, MO) for $10 \mathrm{~min}$. In situ hybridization was performed by incubating the embryos in hybridization mix solution at $70^{\circ} \mathrm{C}$ for $5 \mathrm{~h}$, prior to a further overnight incubation at $70^{\circ} \mathrm{C}$ with the myoD probe (ZFIN:ZDB-GENE-980526-561). Following a series of washes in sodium citrate solutions and then PBS, the embryos were incubated overnight at $4^{\circ} \mathrm{C}$ with anti-DIG-alkaline phosphatase antibody specific for the myoD probe (Invitrogen, Carlsbad, CA), and, following further washes in PBS, immunopositivity was revealed using staining solutions of nitro blue tetrazolium (Sigma) and 5-bromo 4-chloro 3-indolyl phosphate (Sigma). The stained embryos were then transferred to glycerol (Molekula) for microscopy and imaging.

Immunolocalization was performed for the muscle marker $\alpha$-actinin, the neural crest marker Sox9, and the lateral plate mesoderm marker Tbx5, by adapting previously published methods [27]. In brief, RAR $\gamma$-agonist-treated and control embryos were fixed in $4 \%$ PFA at $4{ }^{\circ} \mathrm{C}$ overnight at the time points indicated in "Results" section and then washed repeatedly in PBS-Tween (PBS-T; 90\%:10\%) before an enzymatic digestion with collagenase $(1 \mathrm{mg} / \mathrm{mL}$; Sigma) for $75 \mathrm{~min}$ at $37^{\circ} \mathrm{C}$. The embryos were then incubated with antibodies specific for $\alpha$-actinin (1/100 dilution in PBS-T; Sigma) or Sox9 (1/100 dilution in PBS-T, Clone ab76997; Abcam Ltd., Cambridge, UK) or Tbx5 (Genetix, Irvene, $\mathrm{CA}$ ) at $4^{\circ} \mathrm{C}$ overnight. Embryos were then washed repeatedly in PBS-T prior to incubation with Alexa 594conjugated anti-mouse antibodies for $\alpha$-actinin or Sox 9 (1/ 250 dilution in PBS-T; Invitrogen Ltd.) at $4{ }^{\circ} \mathrm{C}$ overnight, washing again in PBS-T, and then mounted in glycerol for microscopy and image capture. For Tbx5 immunolocalization, embryos were similarly washed repeatedly in PBS-T after incubation with the primary antibodies, after which immunopositivity was revealed using biotin-anti-rabbit secondary antibodies (1/400 in PBS-T; Vector Labs, Peterborough, UK) followed by further washes and incubation with streptavidin-linked fluorescein isothiocyanate (FITC) (1/50 in PBS-T; Vector Labs), adapting methods previously described [28].

\section{Alizarin red staining for bone formation}

Alizarin red staining was performed to examine the presence of bone by adapting previously published methods [25]. In brief, RAR $\gamma$-agonist-treated and control embryos were euthanized at 5 days postfertilization (dpf) and fixed in $4 \%$ PFA at $4{ }^{\circ} \mathrm{C}$ overnight and then washed in PBS-T prior to staining in a solution of alizarin red $(96 \%$ of $0.5 \%$ potassium hydroxide: $4 \%$ of $0.1 \%$ alizarin red S; Molekula) for $3 \mathrm{~h}$ at room temperature. After staining, the embryos were washed and mounted in glycerol prior to microscopy and image capture.

\section{Image capture and analysis}

Phase-contrast or bright-field digitized images were captured using a Nikon DXM1200 camera attached to a Nikon SMZ745T stereomicroscope, a Leica DFX 300FX camera attached to a Leica MZ 16FA stereomicroscope, or a Jenoptik camera attached to a Ceti inverted microscope. A
Leica DFX 300FX camera, attached to a Leica MZ 16FA stereomicroscope, was also used to capture fluorescence images of the transgenic zebrafish embryos and of $\alpha$ actininimmunostained embryos. Laser scanning confocal microscopy was performed with the Leica Microsystems DM6000BSP57CS confocal system to generate $z$ stacks of Sox9- and Tbx5-immunostained zebrafish embryos. These were then converted into 3 dimensional (3D) projected images of the entire ventral-dorsal or lateral aspects. The projected images of Sox9-immunostained zebrafish embryos were used to quantify the number of Sox9-immunopositive cells present in the total head region that was anterior from the anterior aspect of the otic vesicle. Phase-contrast digitized images were captured at low magnification $(4 \times$ lens $)$ and these images were analyzed to determine the embryo length along the antero-posterior axis using Image $\mathbf{J}$ software.

\section{Caudal fin transection}

The AB strain or Tcf:mini-p transgenic zebrafish embryos at 2 or $3 \mathrm{dpf}$, respectively, were anesthetized with $0.4 \%$ Tricaine (Sigma) and then placed on a glass slide and the caudal fin was transected using a thin scalpel blade (SLS). The embryos were then transferred to fresh Hank's saline or E3 media in an incubator at $28.5^{\circ} \mathrm{C}$ for those periods of fin regrowth indicated in "Results" section. The embryos were treated with the RAR $\gamma$ agonist $(10 \mathrm{nM})$ or carrier alone immediately following caudal fin transection. In some experiments, the $\mathrm{AB}$ strain embryos were treated with an RAR $\gamma$-specific antagonist at $3 \mathrm{dpf}$ (following RAR $\gamma$ agonist treatment at $2 \mathrm{dpf}$ ) or subjected to washout of the RAR $\gamma$ agonist at $3 \mathrm{dpf}$.

\section{Statistical analysis}

Data were evaluated for normal distribution using the D'Agostino and Pearson omnibus normality test. One-way or two-way analysis of variance (ANOVA) was used to assess the relationships between treatment of zebrafish embryos with different concentrations of the RAR $\gamma$ agonist and fish length or the growth of treated versus control embryos over time, with post hoc analysis. Student's paired $t$-tests or Mann-Whitney $U$ tests were used to examine differences between treatment versus control groups for hox gene expression or the prevalence of Sox9-immunopositive cells, according to whether the data were normally or not normally distributed, respectively. All statistical analyses were performed using GraphPad Prism software. Values were considered statistically significant, as indicated in "Results" section, at $P \leq 0.05(*)$. Unless otherwise indicated all data have been presented as means \pm standard deviations where a minimum of $n=3$ procedures were performed for all experiments. The total number of embryos in these experiments that were pooled and analyzed have been shown in figure legends.

\section{Results}

Treatment of zebrafish embryos with the RAR agonist inhibited antero-posterior growth and decreased somite formation

Treatment of zebrafish embryos at $4 \mathrm{hpf}$ with the RAR $\gamma$ agonist was associated with clear morphological differences 
during development, with the main difference being a reduced antero-posterior axis length (Fig. 1A). The reduction in fish length was RAR $\gamma$ agonist dose dependent. Treatment of embryos with $1 \mathrm{nM}$ RAR $\gamma$ agonist had no obvious effects on zebrafish growth while treatments with the RAR $\gamma$ agonist at $80 \mathrm{nM}$ (or above) caused severe truncation (Fig. 1B). The RAR $\gamma$-agonist-treated embryos also developed cardiac edema and, beyond $3 \mathrm{dpf}$, embryos treated with the higher doses of the RAR $\gamma$ agonist lost viability (data not shown). Therefore, all further analyses were performed using the RAR $\gamma$ agonist at $10 \mathrm{nM}$, which was not lethal. Changes in the antero-posterior length of embryos treated with $10 \mathrm{nM}$ RAR $\gamma$ agonist were most markedly affected from $2 \mathrm{dpf}$ onward, such that the treated embryos were significantly shorter than the control embryos at 3-5 dpf (Fig. 1C).

Somite formation was observed using an indicator transgenic fish line (hspGFF55B), which has green fluorescent protein (GFP) expression in its somites and heart [21]. At $3 \mathrm{dpf}$, the number of somites present in $\operatorname{RAR} \gamma$ agonist $(10 \mathrm{nM})$-treated embryos in this transgenic fish line was consistently observed to be 25 , which is 5 fewer than the 30 somites that were observed in the control transgenic embryos at the same stage of development (and is the normal somite number in adult zebrafish) [29] (Fig. 2A). In situ
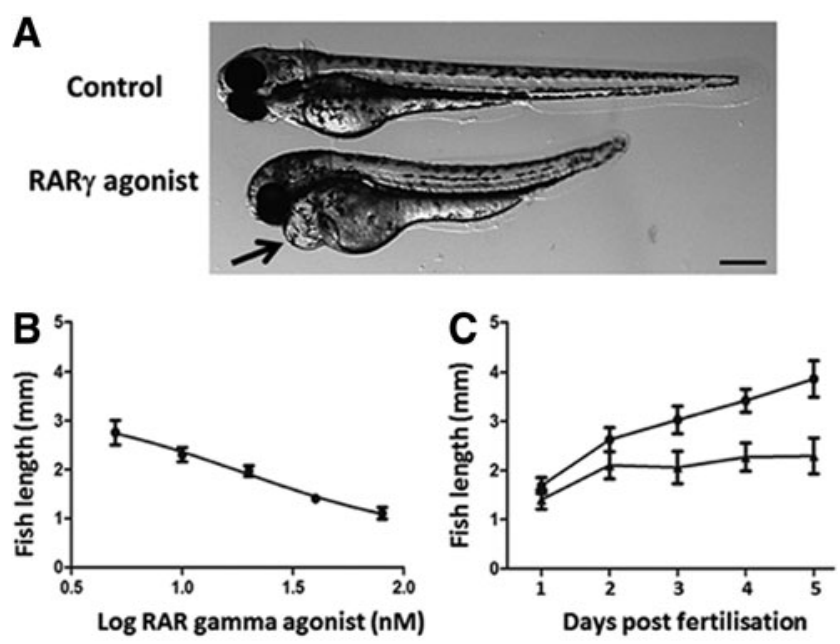

FIG. 1. Treatment of embryonic zebrafish at $4 \mathrm{~h}$ postfertilization (hpf) with a retinoic acid receptor $\gamma(\mathrm{RAR} \gamma)$ agonist was associated with a dose-dependent decrease in the antero-posterior length and slower axial growth. (A) A representative phase-contrast microscopy image showing the left lateral view of RAR $\gamma$ agonist $(10 \mathrm{nM})$-treated and control AB strain zebrafish embryos at 3 days postfertilization (dpf). The RAR $\gamma$-agonist-treated embryo length was markedly shorter than the control. Cardiac edema was also evident (arrow). Scale bar represents $250 \mu \mathrm{m}$. (B) There was a significant relationship between $\operatorname{RAR} \gamma$ agonist doses and the axial length of zebrafish embryos at $3 \mathrm{dpf}$, with a significantly lesser length versus control at doses of $10 \mathrm{nM}$ and above $[P \leq 0.0001$; analysis of variance (ANOVA) with post-hoc analysis; data shown as means \pm standard deviations (SDs), pooled from three independent experiments]. (C) RAR $\gamma$ agonist (10 nM)-treated zebrafish embryos had slower growth rates than control embryos, most markedly from 3 to $5 \mathrm{dpf}$ (data shown as means $\pm \mathrm{SDs}$, from $n=10 \mathrm{RAR} \gamma$ agonist-treated versus $n=10$ control fish). hybridization for $m y o D$, which specifies myocyte differentiation, as well as immunolocalization for the myocyte marker $\alpha$-actinin, was performed to further assess somite formation. Although a somewhat weaker level of myoD expression was seen in the anterior regions of the RAR $\gamma$ agonist-treated embryos compared with control embryos (Fig. 2B, C), this was not associated with a clear inhibition in myocyte formation as delineated by $\alpha$-actinin immunoreactivity (Fig. 2D, E). Further, the pattern of $\alpha$-actinin immunoreactivity confirmed that there was the same reduced number of somites (ie, 25 somites at $3 \mathrm{dpf}$ ) in the RAR $\gamma$ agonist-treated embryos compared with control embryos (ie, 30 somites at $3 \mathrm{dpf}$ ). Therefore, treatment with an RAR $\gamma$ agonist was associated with decreased axial length and a specific reduction in the formation of somites without a uniform inhibition of myocyte differentiation.

\section{Differential hoxc11a and hoxb13a expression patterns demonstrated that the reduced antero-posterior length in RAR $\mathrm{r}$-agonist-treated zebrafish embryos was associated with a loss of posterior tissues}

Precise expression of the hox gene family is necessary for normal antero-posterior axis formation in vertebrates [30]. Transgenic fish lines, SAGFF155A and hspGFFDMC28B, were used to indicate the expression patterns of hoxclla and hoxb13a in RAR $\gamma$-agonist-treated versus control embryos (Fig. 3). As shown, hoxc1la was expressed from near the anal region to the caudal regions in the $\operatorname{RAR} \gamma$-agonisttreated and control embryos at $2 \mathrm{dpf}$ (Fig. 3A), although the cranial start of hoxclla expression was three to four somites more posterior in the $\operatorname{RAR} \gamma$-agonist-treated embryos. In sharp contrast, the expression of hoxb13a at $2 \mathrm{dpf}$ (Fig. 3B) was only seen in the most posterior caudal region of the control embryos, as well as in the anal region, whereas no hoxb13a expression was seen in the RAR $\gamma$-agonist-treated embryos. These patterns of expression were consistent in all treated and control zebrafish embryos throughout their development. The distance from the anterior end of the head to the anal regions of either the wild-type ( $A B$ strain; see Fig. 1A) or the hox gene reporter fish lines was similar in the RAR $\gamma$-agonist-treated and control embryos. Conversely, there was a marked decrease in the distance from the anal regions to the most caudal end of the $\operatorname{RAR} \gamma$-agonist-treated embryos compared with control embryos. Hence, these differential patterns of hox gene expression indicate that $\operatorname{RAR} \gamma$ agonism adversely prevented the formation of the most posterior somites and caudal fin, which was associated with a complete loss of hoxb13a expression.

\section{Hoxb13a expression and growth of the caudal fin were rescued by washout of the $R A R \gamma$ agonist or additional treatment with the $R A R \gamma$ antagonist}

To examine whether the loss of hox gene expression after $\operatorname{RAR} \gamma$ agonist treatment may have been due to irreversible teratogenic effects early in the development of the zebrafish, rather than being targeted toward the hox gene pathway, we examined whether hoxb13a expression returned following treatment with the RAR $\gamma$ agonist at $4 \mathrm{hpf}$ and then either washout of the RAR $\gamma$ agonist at $23 \mathrm{hpf}$ or cotreatment with 

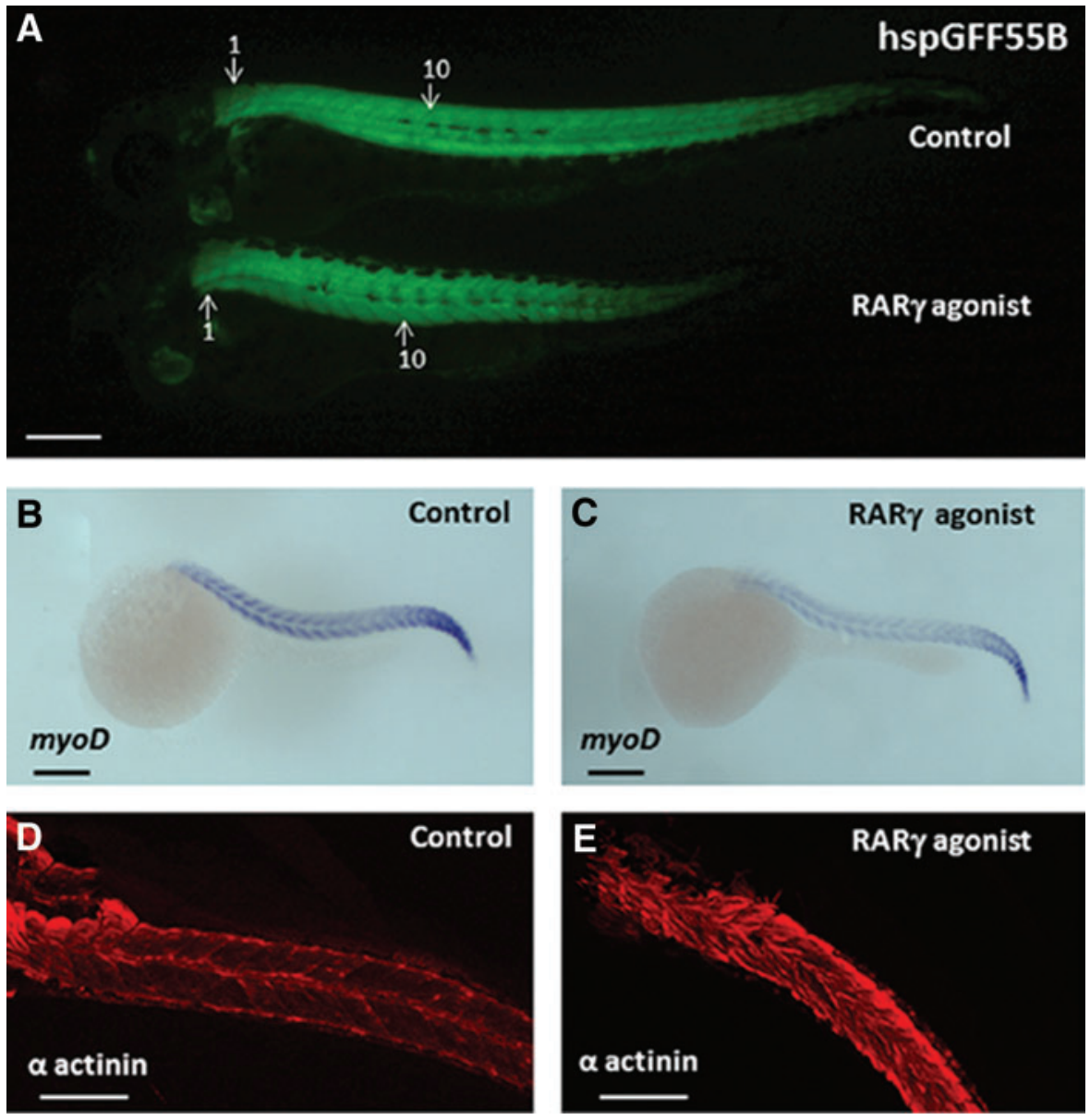

FIG. 2. Treatment of embryonic zebrafish with a RAR $\gamma$ agonist was associated with a reduction in somite formation. (A) A representative fluorescence microscopy image showing the left lateral view of RAR $\gamma$-agonist-treated (10 nM) and control hspGFF55B transgenic zebrafish embryos at $3 \mathrm{dpf}$ where the somites are indicated by green fluorescent protein (GFP) expression. There were five fewer somites present in the RAR $\gamma$-agonist-treated embryos (25 somites) compared with the control embryos (30 somites), but there was no discernible difference in the size of the individual somites present, as shown by counting from anterior somites $1-10$. These differences were seen in every case of RAR $\gamma$-agonist-treated versus control embryos ( $n=3$ independent experiments). (B, C) Representative bright-field images of in situ hybridization for $m y o D$ expression in the RAR $\gamma$-agonist-treated and control AB strain zebrafish embryos at $22 \mathrm{hpf}$, where a slightly reduced signal was observed in somitic myoD expression in the RAR $\gamma$-agonist-treated embryos (myoD expression was determined in 14 RAR $\gamma$ agonist-treated embryos versus 13 control embryos.). (D, E) Representative fluorescence microscopy images of $\alpha$ actinin immunolocalization in RAR $\gamma$-agonist-treated and control AB strain zebrafish embryos at 3 dpf. No discernible differences in immunopositivity were seen. An identically reduced number of somites as that seen in the hspGFF5B transgenic line, that is, by five somites in RAR $\gamma$-agonist-treated embryos compared with control embryos at $3 \mathrm{dpf}$, was also seen in the RAR $\gamma$-agonisttreated embryos immunostained for $\alpha$ actinin (immunostaining for $\alpha$ actinin was performed in 14 control and 14 RAR $\gamma$ agonist-treated embryos.). Scale bars represent $250 \mu \mathrm{m}$. Color images available online at www.liebertpub.com/scd

the RAR $\gamma$ antagonist, also at $23 \mathrm{hpf}$. As shown (Fig. 4), no hoxb13a expression was observed in the anal region and the most posterior region of the tail or caudal fin in RAR $\gamma$ agonist-treated embryos at $5 \mathrm{dpf}$ (Fig. 4A). In contrast, in the embryos that were treated with the RAR $\gamma$ agonist at $4 \mathrm{hpf}$ and then subsequently treated with the RAR $\gamma$ antagonist at $23 \mathrm{hpf}$, increased hoxb13a expression was seen in both anal and the tail regions at $5 \mathrm{dpf}$ (Fig. 4B, C). This pattern of elevated hoxb13a gene expression at $5 \mathrm{dpf}$ was also evident in embryos in which the RAR $\gamma$ agonist was washed out at 23 hpf (data not shown). Moreover, data analysis of caudal fin length also showed that both washout and RAR $\gamma$ antagonist treatment caused significant increase in caudal fin length at $5 \mathrm{dpf}$ compared with RAR $\gamma$-agonist-treated em- bryos (Fig. 4D, E). Hence, these data suggest that the inhibitory effects of the RAR $\gamma$ agonist on hoxb13a expression and caudal fin formation were not due to early irreversible teratogenic wherein hox gene expression was not possible.

Treatment with the RARy agonist caused changes in head morphology, loss of anterior cranial bones, and loss of anterior lateral line ganglia, but did not affect the prevalence of Sox 9-immunopositive neural crest cells

The head morphology of RAR $\gamma$-agonist-treated embryos was markedly different from that of control embryos. At $3 \mathrm{dpf}$, there was a clear loss of the most anterior parts of the 

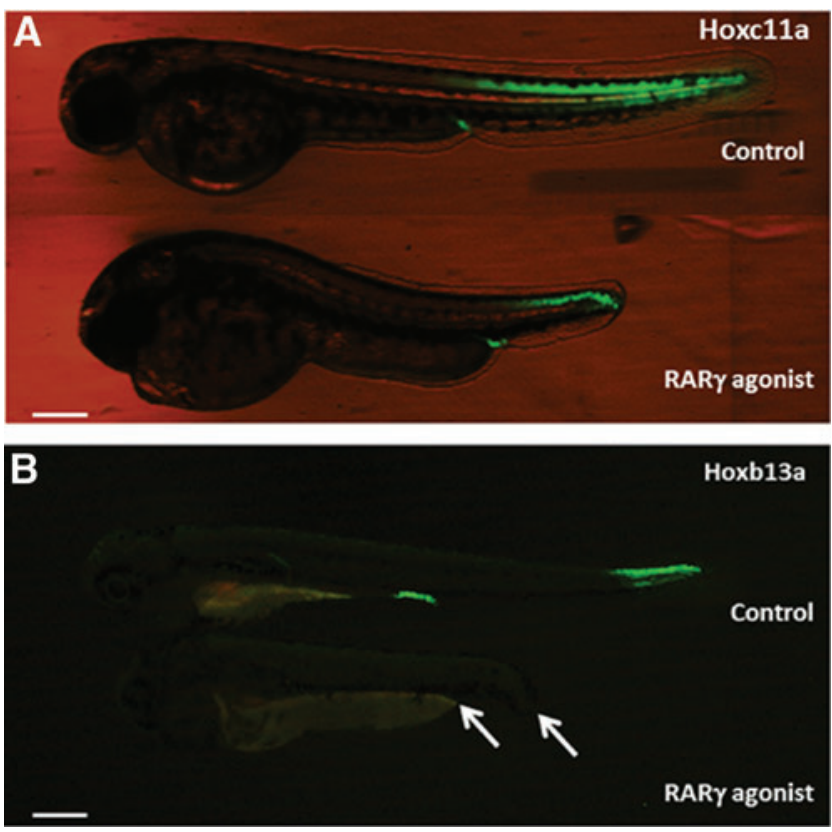

FIG. 3. Differential patterns of hoxc11a and hoxb13a expression in transgenic reporter zebrafish embryos demonstrated that the reduced axial length of $\operatorname{RAR} \gamma$-agonist-treated embryos was associated with loss of their most posterior regions. (A) Representative fluorescence microscopy images showing GFP expression in the hspGFF155A transgenic zebrafish reported line for hoxc11a expression at $3 \mathrm{dpf}$, where a similar pattern of expression was seen in the RAR $\gamma$-agonist-treated and control embryos ( $n=3$ independent experiments). (B) Representative fluorescence microscopy images showing GFP expression in the hspGFFDMC28B transgenic zebrafish reporter line for hoxb13a expression at $3 \mathrm{dpf}$. In contrast to the control embryos, RAR $\gamma$-agonist-treated embryos exhibited a complete loss of GFP expression in the tail, as well as in the anal region (arrows). The loss of hoxb13a expression was seen in every RAR $\gamma$-agonist-treated hspGFFDMC28B transgenic zebrafish embryos at $3 \mathrm{dpf}$ ( $n=3$ independent experiments). Scale bars represent $250 \mu \mathrm{m}$. Color images available online at www liebertpub.com/scd

head, that is, the primordia of the mouth and jawbone region, as well as an apparent loss of pharyngeal arches in the RAR $\gamma$-agonist-treated embryos compared with control embryos (Fig. 5A, B). Alizarin red staining of embryos at $5 \mathrm{dpf}$ confirmed a complete lack of anterior cranial bones, including the maxillary, the hyomandibular, and the opercle bones, as well as reduced formation of the cerebrobrachial bones in RAR $\gamma$-agonist-treated embryos compared with control embryos (Fig. 5C, D). The HGn39D transgenic line was used to examine neural tissues of the lateral line system within the anterior regions of the head [23]. This analysis demonstrated a loss of anterior lateral line ganglia in the RAR $\gamma$ agonist-treated embryos at $3 \mathrm{dpf}$ compared with controls at the same time point (Fig. 5E), but no clear differences were seen in either the posterior lateral line ganglia or the lateral line itself. Immunolocalization of Sox9, which is a marker for neural crest cells [31], showed that there was no clear difference in the prevalence of Sox9-immunopositive cells between RAR $\gamma$-agonist-treated and control embryos at $25 \mathrm{hpf}$, but that Sox9-immunopositive cells then decreased in number in the anterior regions of the head in the RAR $\gamma$-agonist-treated em-
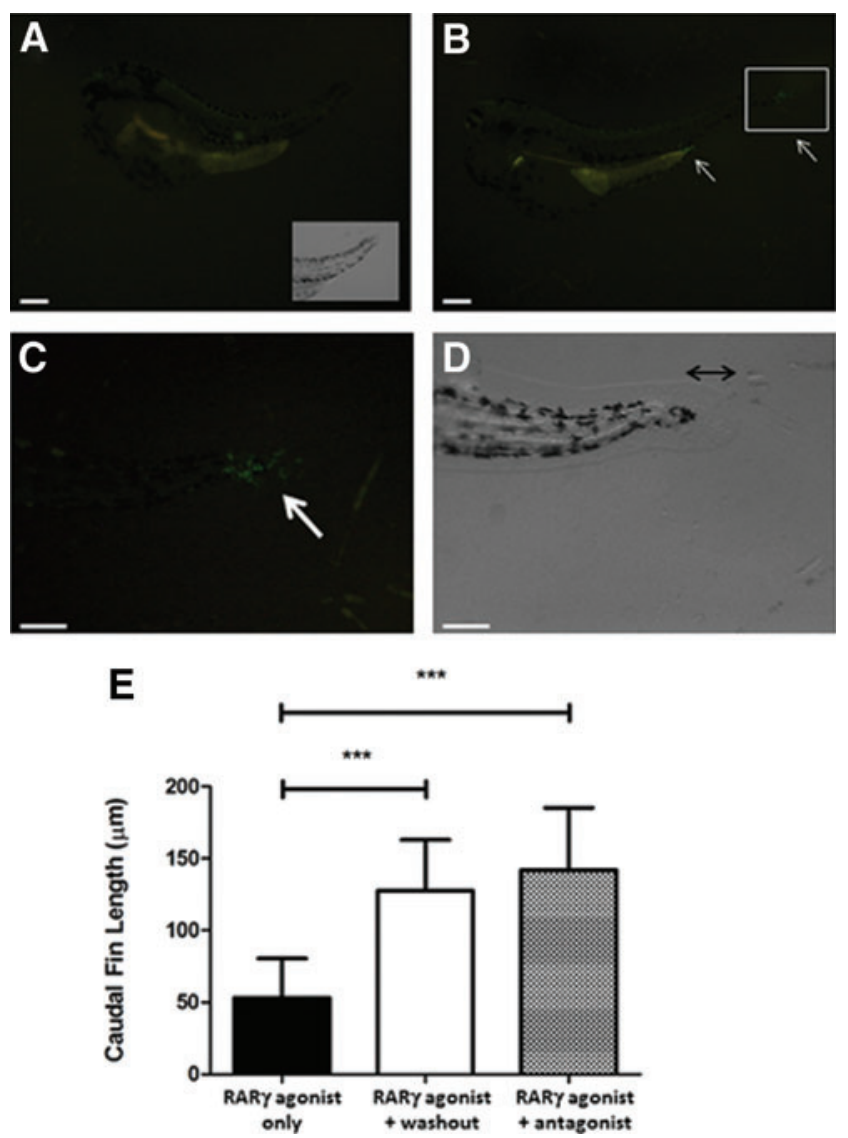

FIG. 4. The effects of a RAR $\gamma$ agonist on hoxb13a and caudal fin outgrowth were reversed by agonist washout or cotreatment with a RAR $\gamma$ antagonist. Representative fluorescence microscopy image showing GFP expression in the hspGFFDMC28B transgenic zebrafish reported line for hox$b 13 a$ expression at $5 \mathrm{dpf}$, in which the embryos were treated with RAR $\gamma$ agonist at $4 \mathrm{hpf}$ (A) or were treated with the agonist at this time and then cotreated with the RAR $\gamma$ antagonist at $23 \mathrm{hpf}(\mathbf{B}$, with higher magnification of the tail region shown in $\mathbf{C}$ ). Representative bright-field microscopy images show the complete loss of the caudal fin in RAR $\gamma$-agonist-treated embryos (inset A) and the extent to which the caudal fin had grown in the embryos treated with the RAR $\gamma$ antagonist (D). (E) The graph shows the comparative length of the caudal fin in the RAR $\gamma$-agonist-treated embryos versus the washout or RAR $\gamma$-antagonist-cotreated embryos at $5 \mathrm{dpf}$. Data are shown as means \pm SDs, pooled from four independent experiments. Scale bars represent $250 \mu \mathrm{m}$. Color images available online at www.liebertpub.com/scd

bryos only by 60 hpf (Fig. 6). Hence, RAR $\gamma$ agonist treatment was associated both with a loss of cranial neural crest stem/ progenitor cells as well as loss of the most anterior cranial tissues that these cells form.

\section{Treatment with the RAR $\gamma$ agonist reversibly blocked pectoral fin outgrowth}

Although the pectoral fin bud was clearly present, RAR $\gamma$ agonist-treated embryos did not grow the pectoral fin (Fig. 7A, B). Immunolocalization for the transcription factor Tbx5a, which is a marker of the lateral plate mesoderm stem/ progenitor cells that form the pectoral fin as well as the heart 

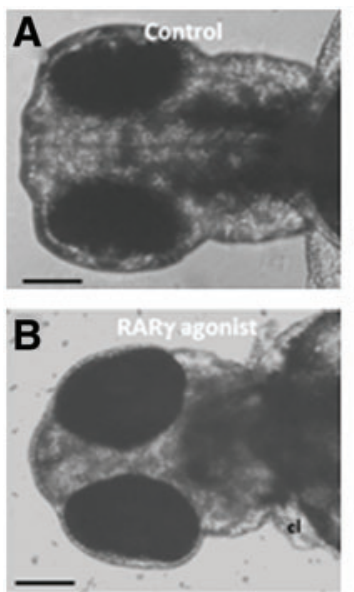
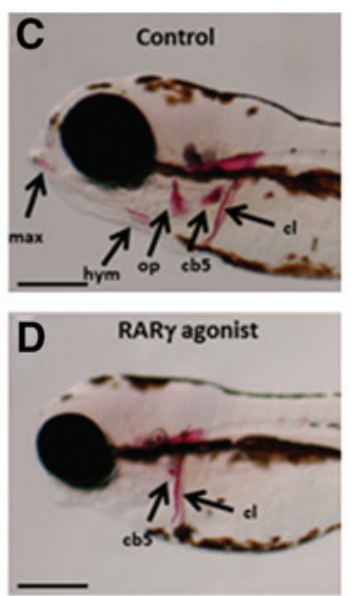

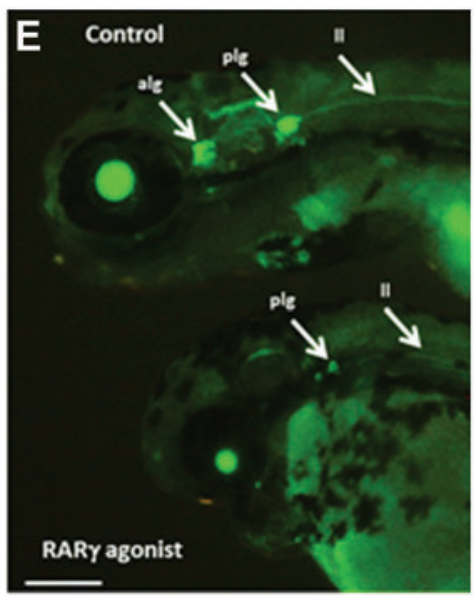

FIG. 5. Treatment of zebrafish embryos with a RAR $\gamma$ agonist was associated with loss of cranial tissues derived from the neural crest. (A, B) Representative phase-contrast microscopy images showing head morphologies in RAR $\gamma$-agonist-treated and control $\mathrm{AB}$ strain embryos at $3 \mathrm{dpf}$. The pharyngeal arches were visible in the control embryos only. (C, D) Representative bright-field microscopy images of alizarin red S-stained AB strain embryos showing that all of the cranial bones were absent in RAR $\gamma$-agonist-treated embryos at $5 \mathrm{dpf}$ except for the most posterior part of the cerebrobranchial 5 (cb5) bone and the cleithrum (cl) bones. Other bones labeled are as follows: hyomandibular (hym), maxillary (max), and opercle (op). All of the control embryos showed normal cranial bones, while all of the RAR $\gamma$-agonist-treated embryos showed a loss of cranial bones at $5 \mathrm{dpf}$ ( $n=3$ independent experiments). (E) A representative confocal microscopy image of the transgenic zebrafish HGn39D reporter line, demonstrating the specific loss of GFP signal in the anterior lateral line ganglia (alg) of RAR $\gamma$-agonist-treated embryos only at $3 \mathrm{dpf}$, but not in the posterior lateral line ganglia (plg) or the lateral line (11) itself, all of which were evident in control embryos at the same stage. All the control HGn39D transgenic zebrafish embryos had intact anterior later line ganglions, while all of the RAR $\gamma$-agonist-treated HGn39D transgenic zebrafish embryos showed loss of anterior lateral line ganglions ( $n=3$ independent experiments). Scale bars represent $250 \mu \mathrm{m}$. Color images available online at www.liebertpub.com/scd
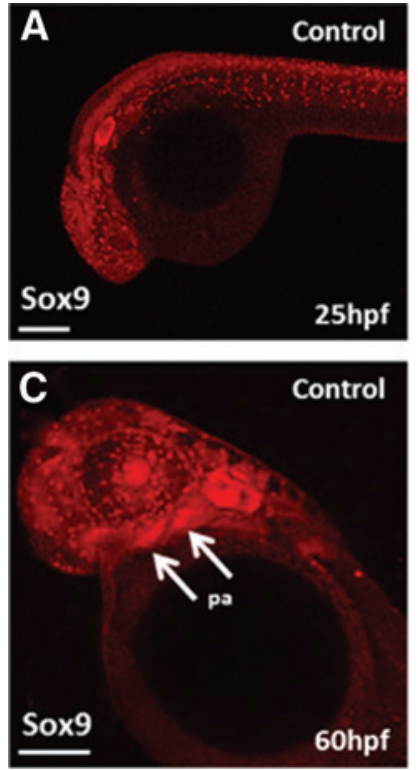
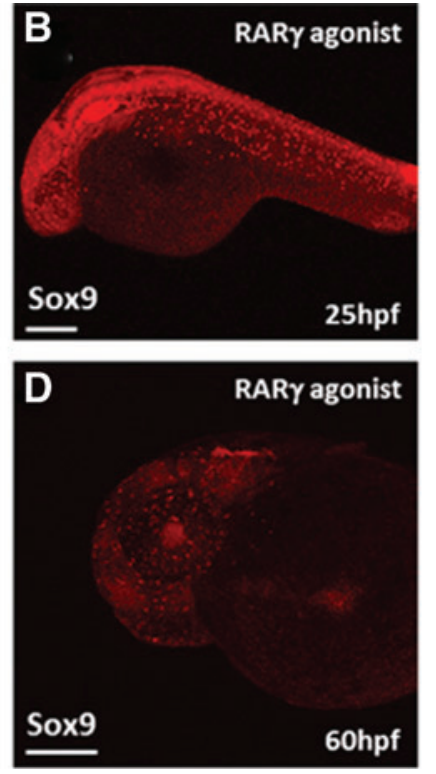

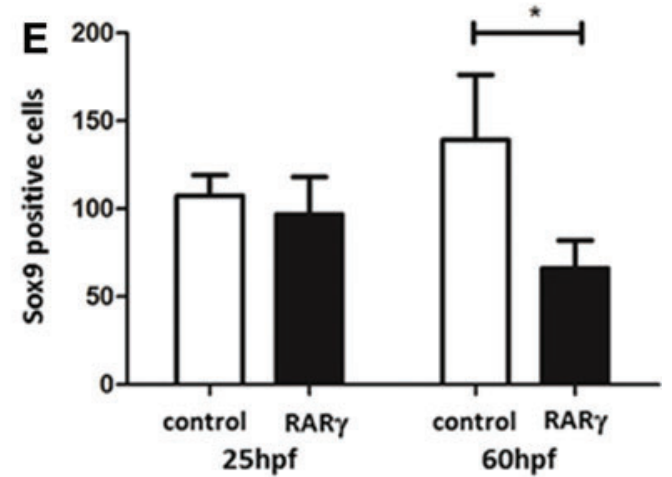

FIG. 6. Treatment of zebrafish embryos with a RAR $\gamma$ agonist was associated with loss of Sox9-immunopositive cranial neural crest stem/progenitor cells. (A-D) Representative confocal-microscopy-projected images of $z$ stacks through the entire lateral perspective of AB strain zebrafish following Sox9 immunolocalization are shown. Sox 9 immunopositivity was observed in the developing pharyngeal arches (pa) of control embryos only at $60 \mathrm{hpf}$ (arrows in C), but were not seen in RAR $\gamma$-agonist-treated embryos. A similar number of Sox9-immunopositive pictures was seen in RAR $\gamma$ agonist and control embryos at $25 \mathrm{hpf}(\mathbf{A}, \mathbf{B})$. However, reduced numbers of Sox9-immunopositive cells were observed in the RAR $\gamma$-agonisttreated embryos at $60 \mathrm{hpf}$ compared with the control embryos (C-E). Data are shown as means \pm SDs, pooled following immunostaining and scores of three control and six RAR $\gamma$-agonist-treated embryos $(P \leq 0.05$; Mann-Whitney $U$ test). Scale bars represent $250 \mu \mathrm{m}$. Color images available online at www.liebertpub.com/scd 

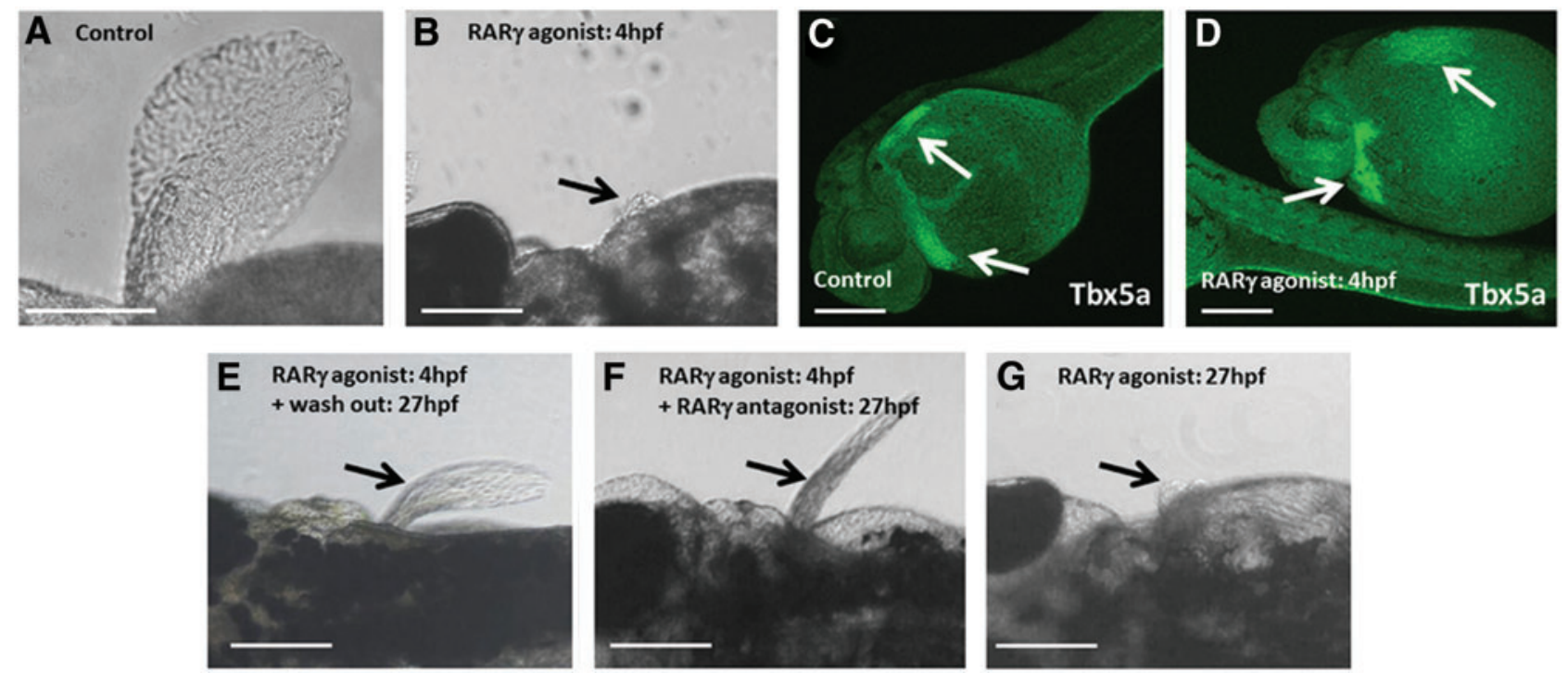

FIG. 7. Treatment of zebrafish embryos with a RAR $\gamma$ agonist was associated with a reversible block in pectoral fin outgrowth with no evident changes in loss of Tbx5 expression in the lateral plate mesoderm at 27 hpf. (A, B) Representative phase-contrast microscopy images showing normal outgrowth of the pectoral fin in control AB strain embryos at 3 dpf and the complete loss of pectoral fin outgrowth that was observed in RAR $\gamma$-agonist-treated embryos at the same time point. All the control embryos showed normal pectoral fin outgrowth, while all the treated embryos showed loss of pectoral fin outgrowth at $3 \mathrm{dpf}$ ( $n=3$ independent experiments). (C, D) Representative confocal-microscopy-projected images of $z$ stacks through the entire lateral perspective of AB strain zebrafish following Tbx5 immunolocalization. As shown, a similar distribution of Tbx5 immunopositivity was seen in the lateral plate mesoderm and heart regions (both arrows) at 27 hpf in the RAR $\gamma$-agonist-treated and control embryos (following immunostaining in 10 control and 10 RAR $\gamma$-agonist-treated embryos). (E-G) Representative phase-contrast microscopy images are shown. Pectoral fin outgrowth in AB strain embryos that had been treated with the RAR $\gamma$ agonist at $4 \mathrm{hpf}$ was restored by (E) washing out the RAR $\gamma$ agonist at $27 \mathrm{hpf}$. All the RAR $\gamma$-agonist-treated embryos which agonist was washed out $27 \mathrm{hpf}$ showed pectoral fin regrowth $(n=3$ independent experiments) or (F) adding an equal dose $(10 \mathrm{nM})$ of the RAR $\gamma$ antagonist at $27 \mathrm{hpf}$. All the RAR $\gamma$-agonist-treated embryos which agonist was added antagonist at $27 \mathrm{hpf}$ showed pectoral fin regrowth $(n=2$ independent experiments). (G) Conversely, pectoral fin outgrowth in control embryos was completely blocked when control media were replaced with the RAR $\gamma$ agonist supplemented media at $27 \mathrm{hpf}$. All of the control embryos that were subsequently treated with RAR $\gamma$ agonist at $27 \mathrm{hpf}$ showed a loss of pectoral fin regrowth ( $n=3$ independent experiments). Scale bars represent $250 \mu \mathrm{m}$. Color images available online at www.liebertpub.com/scd

[32,33], showed that Tbx-5-immunopositive cells were present in these regions in both the $\operatorname{RAR} \gamma$-agonist-treated and the control embryos at $27 \mathrm{hpf}$ (Fig. 7C, D), which is the time point when pectoral fin outgrowth commences [33]. Hence, there was no loss of lateral plate mesodermal stem/progenitor cells associated with the effects of the RAR $\gamma$ agonist on the pectoral fin, or, indeed, the development of cardiac edema. Embryos were treated with the RAR $\gamma$ agonist from $4 \mathrm{hpf}$ and then the medium containing the RAR $\gamma$ agonist was either replaced with control media (ie, washout) or the same concentration $(10 \mathrm{nM})$ of the RAR $\gamma$ antagonist was added at $27 \mathrm{hpf}$. In both of these experiments, subsequent pectoral fin outgrowth was observed at $3 \mathrm{dpf}$ (Fig. 7E, F). In contrast, when the control embryos were treated with the RAR $\gamma$ agonist at $27 \mathrm{hpf}$, pectoral fin outgrowth was subsequently completely blocked (Fig. 7G). Therefore, treatment with the RAR $\gamma$ agonist was associated with a reversible block in pectoral fin formation, which was independent of Tbx5 expression.

\section{Treatment with the RAR $\gamma$ agonist reversibly blocked caudal fin regeneration}

RAR $\gamma$ is expressed in the caudal regions of the developing zebrafish $[9,10]$ and again during adult caudal fin regeneration after transection [34]. The caudal fin in larval zebrafish can regenerate within 3 days after fin transection at $2 \mathrm{dpf}$ [35]. Therefore, we performed experiments to examine whether $\operatorname{RAR} \gamma$ agonist treatment also affected caudal fin regeneration in zebrafish larvae. Caudal fin regeneration, following transection at $2 \mathrm{dpf}$, was observed in control embryos at $5 \mathrm{dpf}$ (Fig. 8A). In contrast, the regeneration process was completely blocked when the embryos were treated with the RAR $\gamma$ agonist immediately following fin transection (Fig. 8B). When treatment with the RAR $\gamma$ agonist immediately following fin transection at $2 \mathrm{dpf}$ subsequently followed with the addition of the RAR $\gamma$ antagonist $(10 \mathrm{nM})$ or by washout of the RAR $\gamma$ agonist at $24 \mathrm{~h}$ posttransection, then fin regeneration was again observed at $5 \mathrm{dpf}$ (Fig. 8C, D).

Canonical Wnt signaling has been reported as important to blastema formation during zebrafish caudal fin regeneration [36]. The upregulation of canonical Wnt signaling during adult caudal fin regeneration is observed in the Tcf:mini-p reporter zebrafish line, in which GFP expression is driven by the engagement of $\beta$ catenin with the $T c f$ reporter [24]. However, the involvement of canonical Wnt signaling in larval fin regeneration has not been reported. Canonical Wnt signaling in caudal fin rays during normal 

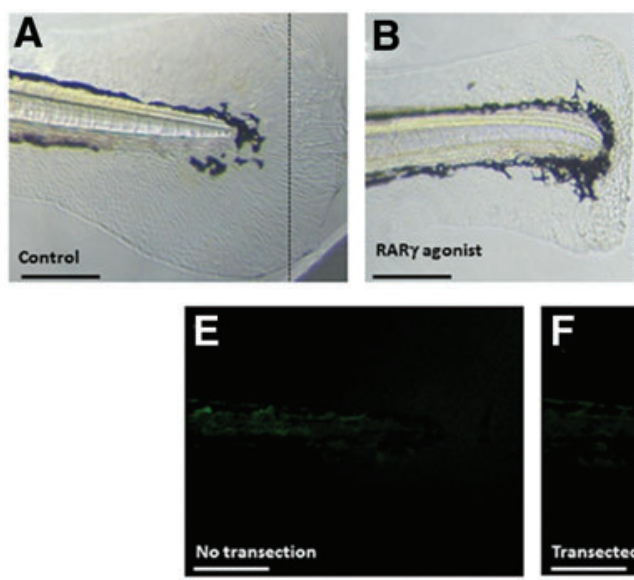
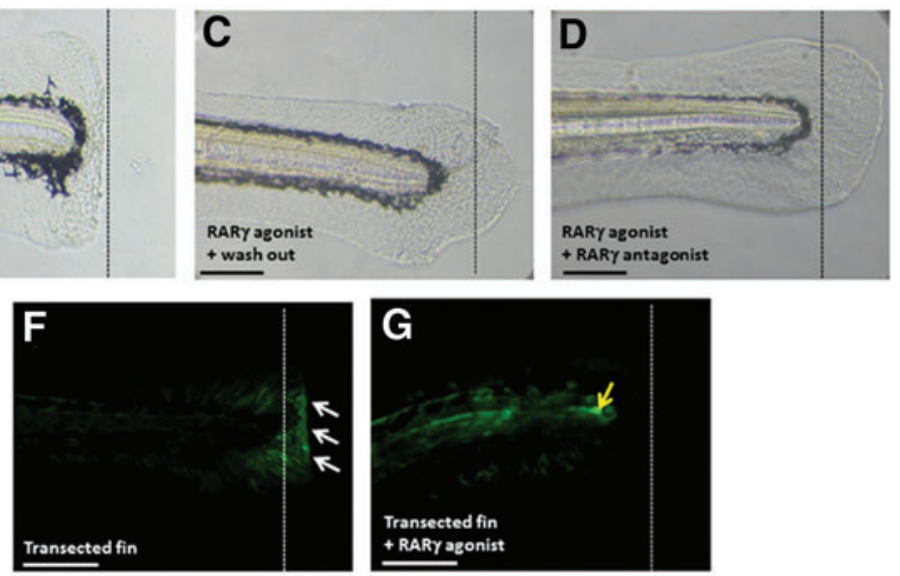

FIG. 8. Treatment of zebrafish embryos with a RAR $\gamma$ agonist was associated with a reversible block in caudal fin regeneration and decreased canonical Wnt signaling. (A, B) Representative phase-contrast microscopy images show caudal fin regeneration in $\mathrm{AB}$ strain control embryos, but not in RAR $\gamma$-agonist-treated embryos, when the embryos were RAR $\gamma$ agonist treated at the same time as fin transection. All of the transected fins in control embryos showed fin regeneration, while none of the transected fins in RAR $\gamma$-agonist-treated embryos showed fin regenerated at $5 \mathrm{dpf}$ ( $n=3$ independent experiments). (C, D) Representative phase-contrast microscopy images are shown. Caudal fin regeneration was restored in RAR $\gamma$-agonist-treated embryos by either $(\mathbf{C})$ washing out the RAR $\gamma$ agonist at 1 day post-transection or (D) adding an equal dose $(10 \mathrm{nM})$ of the RAR $\gamma$ antagonist at 1 day post-transection. These findings were consistent in all embryos $(n=2$ independent experiments). (E-G) Representative fluorescence microscopy images of canonical Wnt signaling in the transgenic zebrafish Tcf:mini-p reporter line. (E) Little GFP expression to indicate canonical Wnt signaling was seen in the caudal tail of nontransected zebrafish embryos at $4 \mathrm{dpf}$. (F) In contrast, there was a marked upregulation in GFP expression, demonstrating increased canonical Wnt signaling in the regenerating caudal fins of control embryos at the same time point, that is, at $4 \mathrm{dpf}$ and 1 day after transection (white arrows). (G) No GFP-evident canonical Wnt signaling was seen in the transected fins of the RAR $\gamma$-agonist-treated embryos at $4 \mathrm{dpf}$ and 1 day after transection. These embryos did not regenerate transected caudal fins. However, increased canonical Wnt signaling was seen in the notochord (yellow arrow). These different patterns of Wnt signaling were seen consistently in all embryos $(n=3$ independent experiments). Scale bars represent $250 \mu \mathrm{m}$. Color images available online at www.liebertpub.com/scd

development was not evident using the reporter fish line by $4 \mathrm{dpf}$ (Fig. 8E). In contrast, following caudal fin transection at $3 \mathrm{dpf}$, increased canonical Wnt signaling was observed in the regenerating blastema at $4 \mathrm{dpf}$ (Fig. 8G). This increased Wnt signal at $4 \mathrm{dpf}$ was not observed in zebrafish embryos that were transected at $3 \mathrm{dpf}$ and immediately treated with the RAR $\gamma$ agonist $(10 \mathrm{nM})$, although there was an evident increase in signal in the notochord (Fig. 8F). Therefore, treatment with the RAR $\gamma$ agonist was associated with a reversible block in caudal fin regeneration, which was associated with decreased canonical Wnt signaling.

\section{Discussion}

This study was performed to examine the potential role of RAR $\gamma$ in regulating embryonic development and tissue regeneration using wild-type and gene reporter embryonic zebrafish as model systems. We demonstrated that treatment of embryonic zebrafish with a RAR $\gamma$-specific agonist had profound developmental consequences, including decreased antero-posterior growth, inhibition of cranial bone and neural tissue formation, and loss of growth of the pectoral and caudal fins, as well as abrogation of caudal fin regeneration following fin transection. We also noted that RAR $\gamma$ agonist-treated fish exhibited cardiac edema. These findings strongly suggest that RAR $\gamma$ activity must be tightly regulated during normal embryonic development and tissue regeneration.
The tissues that were affected by treatment with the RAR $\gamma$ agonist derive from those stem/progenitor cell populations in which $R A R \gamma$ expression is restricted during early embryonic development, that is, in the cranial neural crest, in the lateral plate mesoderm, and in the presomitic mesoderm of the tail bud $[9,10]$. In addition, the tissues affected by the RAR $\gamma$ agonist also mirror those that are similarly affected by morphilino gene knockdown of $R A R \gamma$ (a and b), namely, the pharyngeal arches and pectoral and caudal fins [37]. Further, this phenotype is similar to the effects of RA treatment on embryonic development [38]. Taken together, this suggests that the agonist used in the current study was specific for RAR $\gamma$ in zebrafish, as it has been conclusively demonstrated in mammalian reporter cell lines [15].

The mechanisms involved in the developmental changes observed have been examined using a combination of transgenic reporter fish lines, in situ hybridization and immunohistology for several important genes, and appropriate stem/progenitor cell markers. The shorter body axis formation seen in RAR $\gamma$-agonist-treated embryos was associated with decreased somite formation, as revealed in hspGFF55B transgenic embryos and $\alpha$-actinin immunolocalization. The differential expression of the hox gene family plays an essential role in formation of the anteroposterior axis during vertebrate embryonic development [30]. Hence, we examined the effects of the RAR $\gamma$ agonist on transgenic hox gene reporter fish lines. Analysis of the hoxclla and hoxb13a reporter lines demonstrated that the 
shorter body axis was largely the result of loss of the most posterior region of the embryos. Hoxcl1 is developmentally expressed in the posterior region of the mouse embryo [39] and homozygous knockout of the hoxc cluster results in loss of caudal vertebrae [30,40]. In mice, hoxb13 expression occurs in the tail bud area around E9 [41]. Hoxb13 expression is also found in the developing tail of axolotl and re-expressed in the regenerating tail after transection [42]. These expression patterns suggest that hoxb13 plays an important role in the development and growth of the tail. Conversely, a heterozygous knockout of hoxb13 in mice was shown to cause overgrowth of the tail [43]. Our observation of a complete loss of hoxb13a expression in RAR $\gamma$-agonisttreated zebrafish supports the hypothesis that this gene is essential for the formation of the posterior regions of developing embryos and may be regulated by RAR $\gamma$. Extrasomitic expression of hoxb13a was also seen in the anal fin area of the control embryos, which was completely lost in the RAR $\gamma$-agonist-treated embryos. Other researchers have similarly reported Hoxb13 expression in the hindgut and urogenital area of mice [41]. Hence, our observation further suggests that treatment with the RAR $\gamma$ agonist targeted the expression of hox genes in the posterior regions of the zebrafish embryos, particularly hoxb13a expression, in that no expression was seen following such treatment. We cannot exclude the possibility that hoxb13a expression may have been absent from the RAR $\gamma$-agonist-treated embryos because the tissues in which hoxb13a is normally expressed during development, including the anal area, were not formed. However, the re-expression of hoxb13a in both the anal region and tail region in embryos that were treated at $4 \mathrm{hpf}$ with the RAR $\gamma$ agonist, but then subsequently were the $\operatorname{RAR} \gamma$ agonist was washed out or the embryos were additionally treated with the RAR $\gamma$ antagonist, which was also associated with evident renewed growth of the caudal fin, would suggest that at least such a loss of tissue formation is acutely responsive to the presence of reagents that affect $\operatorname{RAR} \gamma$. The loss of hox gene expression in response to treatment with a RAR agonist is certainly paradoxical as RARE is located within the regulatory region of hox gene clusters [44], which are normally upregulated in response to RA [45-47]. Such a paradox may be resolved if RAR $\gamma$ does not require RA or indeed does not function through RARE to regulate target gene expression.

The marked morphological changes seen in the head of the RAR $\gamma$-agonist-treated embryos were associated with loss of cranial bones and the anterior lateral line ganglia as revealed by alizarin red staining and the HGn39D transgenic fish line, respectively. These tissues form from the neural crest, as well as the placode for the lateral line [48]. This suggests that RAR $\gamma$ agonist treatment may have targeted neural crest stem/progenitor cells, which are known to express $\operatorname{RAR} \gamma[9,10]$. The fact that we saw significantly fewer Sox9-immunopositive cells in the cranial region of the RAR $\gamma$-agonist-treated embryos might be considered to support this hypothesis. However, this difference was only seen in later time points, that is, at $60 \mathrm{hpf}$ but not at $25 \mathrm{hpf}$, even though RAR $\gamma$ is expressed at the earlier time point. Further, even at $60 \mathrm{hpf}$, Sox9-immunopositive cells were still observed in the cranium. Therefore, it is also possible that fewer Sox9-immunopositive cells were prevalent within the anterior cranial regions of the RAR $\gamma$-agonist-treated embryos simply because the anterior tissues did not form. Further research is required to examine whether the loss of Sox9 neural crest stem/progenitor cells following treatment with the RAR $\gamma$ agonist is causal to the loss of anterior cranial tissues observed. However, it is noteworthy that Sox $9 a$ or $\operatorname{Sox} 9 b$ morphilino knockdown and Sox $9 a$ mutant zebrafish embryos were shown to lack cranial skeletal structures $[49,50]$. These developmental defects were associated with Sox9 aberrant neural crest stem/progenitor cell differentiation, rather than any changes in neural crest formation or cell migration. Similarly, we conclude that treatment with the RAR $\gamma$ agonist did not markedly affect the formation of neural crest stem/progenitor cells, as depicted by Sox9-immunopositive cells at $25 \mathrm{hpf}$, but may well have influenced their survival, proliferation, migration, or differentiation thereafter, to adversely affect the development of cranial tissues.

Although almost all of the neural-crest-derived cranial bones were absent or greatly decreased in the RAR $\gamma$ agonist-treated embryos, there were still fully intact cleithrum bones, which also are of neural crest origin [51]. There is no clear explanation for this difference. However, it is interesting that cleithrum bones undergo a process of dermal ossification, unlike other affected cranial bones that undergo endochondral ossification [51,52].

An additional major phenotype seen following treatment with the $\operatorname{RAR} \gamma$ agonist was the loss of pectoral fin outgrowth, despite formation of the fin bud. Other studies have reported that the interaction of RA signaling with expression of $T b \times 5 a$ transcription factor is essential for pectoral fin formation. Increased raldhla2 expression and its localized synthesis of RA in the region of somites two to six, where Tbx5a expression is induced in response to RA, is required for formation of the pectoral fin [32]. Both the Nls (neckless)-mutant zebrafish, which carries a mutation in raldhla2 [16], and embryonic zebrafish treated with the RA synthesis inhibitor diethylaminobenzyldehyde (DEAB) do not express $T b x 5 a$ and do not form pectoral fins [53]. Moreover, loss-of-function Tbx5a mutations block pectoral fin formation, as well as causing heart defects [54]. Zebrafish $T b x 5 a$ expression can be seen from $14 \mathrm{hpf}$ in the lateral late mesoderm, which is the common stem/progenitor cell population for development of the heart and pectoral fins and separate from 24 to $27 \mathrm{hpf}$ [33]. Because the pectoral fins did not form in the RAR $\gamma$-agonist-treated embryos in our study, Tbx5 was considered a potential target gene for $\operatorname{RAR} \gamma$ agonism. However, we found no marked differences in the presence of Tbx5a-immunopositive stem/progenitor cells in the RAR $\gamma$-agonist-treated or control embryos, suggesting that $T b x 5 a$ expression was unaffected. Further, RAR $\gamma$-agonist-washout experiments or cotreatment with a RAR $\gamma$-specific antagonist (as well as the agonist) completely abrogated the block of pectoral fin formation, demonstrating that Tbx5 was functional. Finally, treatment with the RAR $\gamma$ agonist at $27 \mathrm{hpf}$, which we had confirmed was when Tbx5 was present in the lateral plate mesoderm, was also found to completely block pectoral fin outgrowth. Therefore, we conclude that the effect of $\operatorname{RAR} \gamma$ agonist treatment on pectoral fin outgrowth was independent of Tbx5. Potential targets that lie downstream of Tbx5 activity include $f g f$ family genes, that is, $f g f 8, f g f 10$, and $f g f 24$ [55,56], as well as sall4 [57], blimp-1 [58], prdm1 [59], 
beta-CaMK-II [60], and ndrg4 [61]. In addition, hox gene expression was also associated with pectoral fin formation, including hoxa [62], hoxb [63], and hoxd [64,65]. Further study will elucidate whether RAR $\gamma$ agonist treatment alters the expression of each of these genes, but given our finding that hoxb13a was completely inhibited by such treatment, this family is a clear target.

Lastly, we tested whether the RAR $\gamma$ agonist affected tissue regeneration as well as development using transection of the caudal fin as a model because RAR $\gamma$ is expressed in blastemal cells at least during adult zebrafish caudal fin regeneration [34]. Similar to our findings with pectoral fin outgrowth, we found that $\operatorname{RAR} \gamma$ agonist treatment was associated with a complete, but reversible, block on caudal fin regeneration. Canonical Wnt signaling is known to play a major role in caudal fin regeneration [36]. Therefore, we investigated whether this pathway was affected by treatment with the RAR $\gamma$ agonist using the transgenic reporter line Tcf:mini-p [24]. As we hypothesized, the block in caudal fin regeneration following RAR $\gamma$ agonist treatment was associated with an observed reduction in Wnt signaling, suggesting that the Wnt pathway is a target for RAR $\gamma$. However, similarly to our observations of Sox9-immunopositive cells in the cranial neural crest, there is also the possibility that Wnt signaling was not seen following transection of the caudal fin and treatment with the RAR $\gamma$ agonist because the regenerating tissues did not form. Therefore, further study is required to determine whether the evident loss of Wnt signaling following $\operatorname{RAR} \gamma$ agonist treatment is causal to the lack of a regenerative response.

In summary, our results have shown that treatment of zebrafish embryos with a $\operatorname{RAR} \gamma$-specific agonist adversely affected the development and growth of tissues that form from stem/progenitor cells that express $\operatorname{RAR} \gamma[9,10,34]$. These stem/progenitor cell zones [4,32,66] do not express RA-synthesizing enzymes [16,17] and are not exposed to intrinsic RA [18]. This suggests that $R A R \gamma$ functions in the absence of RA ligation. The function of non-RA-ligated RARs is not clear. In mice, RARs were considered to repress gene expression through corepressor activity in the absence of RA ligation [8,14]. However, it has been reported that RARs in zebrafish may not have such corepressor activity [67]. What is clear is that RAR $\gamma$ plays an essential role during embryonic development and likely regulates stem/ progenitor cell populations. Similar to our results using a RAR $\gamma$ agonist, RAR $\gamma$ morphilinos were found to adversely affect the formation of cranial tissue, pectoral fin outgrowth, and the caudal tail [37]. Moreover, in somatic cell reprogramming, RAR $\gamma$ overexpression was related to the rate and efficiency of reprogramming to induced pluripotency [68]. This was suggested to indicate that $\operatorname{RAR} \gamma$ functions to maintain pluripotent stem cell populations. Although the exact function of $\operatorname{RAR} \gamma$ is still not clear, based on our current findings we concur with this hypothesis and further suggest that such activity is seen only when $\operatorname{RAR} \gamma$ is nonligated.

\section{Acknowledgments}

The authors are grateful to Dr. Tohru Ishitani (Kyushu University) for the provision of the transgenic zebrafish Tcf:mini-p reporter line. We are grateful to Charlotte Bland (Aston University) for confocal microscopy and to Anjana
Patel, Georgiana Absoud, and Nisha Patel (all from Aston University) for assistance with other experimental procedures. We are grateful to the Charles Wallace Trust for their financial support of H.A.W. The research leading to these results has received funding from the People Programme (Marie Curie Actions) of the European Union's Seventh Framework Programme FP7/2007-2013/under REA grant agreement number 315902. G.B. and W.E.B.J. are partners within the Marie Curie Initial Training Network DECIDE (decision-making within cells and differentiation entity therapies).

\section{Author Disclosure Statement}

No competing financial interests exist.

\section{References}

1. Glover JC, J-S Renaud and FM Rijli. (2006). Retinoic acid and hindbrain patterning. J Neurobiol 66:705-725.

2. Mark M, NB Ghyselinck and P Chambon. (2006). Function of retinoid nuclear receptors: lessons from genetic and pharmacological dissections of the retinoic acid signaling pathway during mouse embryogenesis. Annu Rev Pharmacol Toxicol 46:451-480.

3. Kam RK, Y Deng, Y Chen and H Zhao. (2012). Retinoic acid synthesis and functions in early embryonic development. Cell Biosci 2:11.

4. Rhinn M and P Dollé. (2012). Retinoic acid signalling during development. Development 139:843-858.

5. Ruberte E, V Friederich, P Chambon and G Morriss-Kay. (1993). Retinoic acid receptors and cellular retinoid binding proteins. III. Their differential transcript distribution during mouse nervous system development. Development 118: 267-282.

6. Gudas LJ. (2013). Retinoids induce stem cell differentiation via epigenetic changes. Semin Cell Dev Biol 24:701705 .

7. Linney E, S Donerly, L Mackey and B Dobbs-McAuliffe. (2011). The negative side of retinoic acid receptors. Neurotoxicol Teratol 33:631-640.

8. Koide T, M Downes, RA Chandraratna, B Blumberg and K Umesono. (2001). Active repression of RAR signaling is required for head formation. Genes Dev 15:2111-2121.

9. Hale LA, A Tallafuss, Y-L Yan, L Dudley, JS Eisen and JH Postlethwait. (2006). Characterization of the retinoic acid receptor genes raraa, rarab and rarg during zebrafish development. Gene Expr Patterns 6:546-555.

10. Waxman JS and D Yelon. (2007). Comparison of the expression patterns of newly identified zebrafish retinoic acid and retinoid X receptors. Dev Dyn 236:587-595.

11. Li E, HM Sucov, KF Lee, RM Evans and R Jaenisch. (1993). Normal development and growth of mice carrying a targeted disruption of the alpha 1 retinoic acid receptor gene. Proc Natl Acad Sci U S A 90:1590-1594.

12. Ghyselinck NB, V Dupe, A Dierich, N Messaddeq, JM Garnier, C Rochette-Egly, P Chambon and M Mark. (1997). Role of the retinoic acid receptor beta (RARbeta) during mouse development. Int J Dev Biol 41:425447.

13. Subbarayan V, P Kastner, M Mark, A Dierich, P Gorry and P Chambon. (1997). Limited specificity and large overlap of the functions of the mouse RAR gamma 1 and RAR gamma 2 isoforms. Mech Dev 66:131-142. 
14. Williams JA, N Kondo, T Okabe, N Takeshita, DM Pilchak, E Koyama, T Ochiai, D Jensen, M-L Chu, et al. (2009). Retinoic acid receptors are required for skeletal growth, matrix homeostasis and growth plate function in postnatal mouse. Dev Biol 328:315-327.

15. Hughes PJ, Y Zhao, RA Chandraratna and G Brown. (2006). Retinoid-mediated stimulation of steroid sulfatase activity in myeloid leukemic cell lines requires RAR $\alpha$ and RXR and involves the phosphoinositide 3-kinase and ERK-MAP kinase pathways. J Cell Biochem 97:327350.

16. Grandel H, K Lun, G-J Rauch, M Rhinn, T Piotrowski, C Houart, P Sordino, AM Küchler, S Schulte-Merker, et al. (2002). Retinoic acid signalling in the zebrafish embryo is necessary during pre-segmentation stages to pattern the anterior-posterior axis of the CNS and to induce a pectoral fin bud. Development 129:2851-2865.

17. Dobbs-McAuliffe B, Q Zhao and E Linney. (2004). Feedback mechanisms regulate retinoic acid production and degradation in the zebrafish embryo. Mech Dev 121:339-350.

18. Shimozono S, T Iimura, T Kitaguchi, S-i Higashijima and A Miyawaki. (2013). Visualization of an endogenous retinoic acid gradient across embryonic development. Nature 496:363-366.

19. Kimmel CB, WW Ballard, SR Kimmel, B Ullmann and TF Schilling. (1995). Stages of embryonic development of the zebrafish. Dev Dyn 203:253-310.

20. Westerfield M. (2000). The Zebrafish Book: A Guide for the Laboratory Use of Zebrafish (Danio rerio). University of Oregon Press, Eugene, OR.

21. Kawakami K, G Abe, T Asada, K Asakawa, R Fukuda, A Ito, $P$ Lal, N Mouri, A Muto, et al. (2010). zTrap: zebrafish gene trap and enhancer trap database. BMC Dev Biol 10:105.

22. Asakawa K, ML Suster, K Mizusawa, S Nagayoshi, T Kotani, A Urasaki, Y Kishimoto, M Hibi and K Kawakami. (2008). Genetic dissection of neural circuits by Tol2 transposon-mediated Gal4 gene and enhancer trapping in zebrafish. Proc Natl Acad Sci U S A 105:1255-1260.

23. Pujol-Marti J, A Zecca, JP Baudoin, A Faucherre, K Asakawa, K Kawakami and H Lopez-Schier. (2012). Neuronal birth order identifies a dimorphic sensorineural map. J Neurosci 32:2976-2987.

24. Shimizu N, K Kawakami and T Ishitani. (2012). Visualization and exploration of Tcf/Lef function using a highly responsive $\mathrm{Wnt} / \beta$-catenin signaling-reporter transgenic zebrafish. Dev Biol 370:71-85.

25. Li N, RN Kelsh, P Croucher and HH Roehl. (2010). Regulation of neural crest cell fate by the retinoic acid and Pparg signalling pathways. Development 137:389394.

26. Thisse C and B Thisse. (2008). High-resolution in situ hybridization to whole-mount zebrafish embryos. Nat Protoc 3:59-69.

27. Codina M, J Li, J Gutierrez, JP Kao and SJ Du. (2010). Loss of Smyhc1 or Hsp90alpha1 function results in different effects on myofibril organization in skeletal muscles of zebrafish embryos. PLoS One 5:e8416.

28. Johnson WE, H Evans, J Menage, SM Eisenstein, A El Haj and S Roberts. (2001). Immunohistochemical detection of Schwann cells in innervated and vascularized human intervertebral discs. Spine (Phila Pa 1976) 26:25502557.

29. Stickney HL, MJ Barresi and SH Devoto. (2000). Somite development in zebrafish. Dev Dyn 219:287-303.
30. Wellik DM. (2007). Hox patterning of the vertebrate axial skeleton. Dev Dyn 236:2454-2463.

31. Li M, C Zhao, Y Wang, Z Zhao and A Meng. (2002). Zebrafish sox9b is an early neural crest marker. Dev Genes Evol 212:203-206.

32. Gibert Y, A Gajewski, A Meyer and G Begemann. (2006). Induction and prepatterning of the zebrafish pectoral fin bud requires axial retinoic acid signaling. Development 133:2649-2659.

33. Albalat R, M Baquero and C Minguillón. (2010). Identification and characterisation of the developmental expression pattern of tbx 5b, a novel tbx 5 gene in zebrafish. Gene Expr Patterns 10:24-30.

34. White JA, MB Boffa, B Jones and M Petkovich. (1994). A zebrafish retinoic acid receptor expressed in the regenerating caudal fin. Development 120:1861-1872.

35. Kawakami A, T Fukazawa and H Takeda. (2004). Early fin primordia of zebrafish larvae regenerate by a similar growth control mechanism with adult regeneration. Dev Dyn 231:693-699.

36. Tal TL, JA Franzosa and RL Tanguay. (2010). Molecular signaling networks that choreograph epimorphic fin regeneration in zebrafish: a mini-review. Gerontology 56:231240.

37. Linville A, K Radtke, JS Waxman, D Yelon and TF Schilling. (2009). Combinatorial roles for zebrafish retinoic acid receptors in the hindbrain, limbs and pharyngeal arches. Dev Biol 325:60-70.

38. Shum ASW, LLM Poon, WWT Tang, T Koide, BWH Chan, Y-CG Leung, T Shiroishi and AJ Copp. (1999). Retinoic acid induces down-regulation of Wnt-3a, apoptosis and diversion of tail bud cells to a neural fate in the mouse embryo. Mech Dev 84:17-30.

39. Hostikka SL and MR Capecchi. (1998). The mouse Hoxc11 gene: genomic structure and expression pattern. Mech Dev 70:133-145.

40. Suemori H and S Noguchi. (2000). Hox C cluster genes are dispensable for overall body plan of mouse embryonic development. Dev Biol 220:333-342.

41. Zeltser L, C Desplan and N Heintz. (1996). Hoxb-13: a new Hox gene in a distant region of the HOXB cluster maintains colinearity. Development 122:2475-2484.

42. Carlson MRJ, Y Komine, SV Bryant and DM Gardiner. (2001). Expression of Hoxb13 and Hoxc10 in developing and regenerating Axolotl limbs and tails. Dev Biol 229: 396-406.

43. Economides KD, L Zeltser and MR Capecchi. (2003). Hoxb13 mutations cause overgrowth of caudal spinal cord and tail vertebrae. Dev Biol 256:317-330.

44. Zhang F, E Nagy Kovács and MS Featherstone. (2000). Murine Hoxd4 expression in the CNS requires multiple elements including a retinoic acid response element. Mech Dev 96:79-89.

45. Popperl H and MS Featherstone. (1993). Identification of a retinoic acid response element upstream of the murine Hox4.2 gene. Mol Cell Biol 13:257-265.

46. Huang D, SW Chen and LJ Gudas. (2002). Analysis of two distinct retinoic acid response elements in the homeobox gene Hoxb1 in transgenic mice. Dev Dyn 223:353370.

47. Oliveira E, M Casado, D Raldúa, A Soares, C Barata and B Piña. (2013). Retinoic acid receptors' expression and function during zebrafish early development. J Steroid Biochem Mol Biol 138:143-151. 
48. Collazo A, SE Fraser and PM Mabee. (1994). A dual embryonic origin for vertebrate mechanoreceptors. Science 264:426-430.

49. Yan Y-L, CT Miller, R Nissen, A Singer, D Liu, A Kirn, B Draper, J Willoughby, PA Morcos, et al. (2002). A zebrafish sox9 gene required for cartilage morphogenesis. Development 129:5065-5079.

50. Yan Y-L, J Willoughby, D Liu, JG Crump, C Wilson, CT Miller, A Singer, C Kimmel, M Westerfield and JH Postlethwait. (2005). A pair of Sox: distinct and overlapping functions of zebrafish sox9 co-orthologs in craniofacial and pectoral fin development. Development 132:10691083.

51. Kague E, M Gallagher, S Burke, M Parsons, T FranzOdendaal and S Fisher. (2012). Skeletogenic fate of zebrafish cranial and trunk neural crest. PLoS One 7:e47394.

52. Eames BF, A DeLaurier, B Ullmann, TR Huycke, JT Nichols, J Dowd, M McFadden, MM Sasaki and CB Kimmel. (2013). FishFace: interactive atlas of zebrafish craniofacial development at cellular resolution. BMC Dev Biol 13:23.

53. Grandel H and M Brand. (2011). Zebrafish limb development is triggered by a retinoic acid signal during gastrulation. Dev Dyn 240:1116-1126.

54. Garrity DM, S Childs and MC Fishman. (2002). The heartstrings mutation in zebrafish causes heart/fin Tbx5 deficiency syndrome. Development 129:4635-4645.

55. Ng JK, Y Kawakami, D Büscher, Á Raya, T Itoh, CM Koth, CR Esteban, J Rodríguez-León, DM Garrity, MC Fishman and JCI Belmonte. (2002). The limb identity gene Tbx 5 promotes limb initiation by interacting with Wnt $2 b$ and Fgf10. Development 129:5161-5170.

56. Fischer S, BW Draper and CJ Neumann. (2003). The zebrafish fgf 24 mutant identifies an additional level of Fgf signaling involved in vertebrate forelimb initiation. Development 130:3515-3524.

57. Harvey SA and MPO Logan. (2006). sall4 acts downstream of tbx5 and is required for pectoral fin outgrowth. Development 133:1165-1173.

58. Lee BC and S Roy. (2006). Blimp-1 is an essential component of the genetic program controlling development of the pectoral limb bud. Dev Biol 300:623-634.

59. Mercader N, S Fischer and CJ Neumann. (2006). Prdm1 acts downstream of a sequential RA, Wnt and Fgf signaling cascade during zebrafish forelimb induction. Development 133:2805-2815.

60. Rothschild SC, CA Easley Iv, L Francescatto, JA Lister, DM Garrity and RM Tombes. (2009). Tbx5-mediated expression of $\mathrm{Ca} 2+/$ calmodulin-dependent protein kinase II is necessary for zebrafish cardiac and pectoral fin morphogenesis. Dev Biol 330:175-184.
61. Qu X, H Jia, DM Garrity, K Tompkins, L Batts, B Appel, TP Zhong and HS Baldwin. (2008). Ndrg4 is required for normal myocyte proliferation during early cardiac development in zebrafish. Dev Biol 317:486-496.

62. Géraudie J and V Borday Birraux. (2003). Posterior hoxa genes expression during zebrafish bony fin ray development and regeneration suggests their involvement in scleroblast differentiation. Dev Genes Evol 213:182-186.

63. Waxman JS, BR Keegan, RW Roberts, KD Poss and D Yelon. (2008). Hoxb5b acts downstream of retinoic acid signaling in the forelimb field to restrict heart field potential in zebrafish. Dev Cell 15:923-934.

64. Sakamoto K, K Onimaru, K Munakata, N Suda, M Tamura, H Ochi and M Tanaka. (2009). Heterochronic shift in Hoxmediated activation of sonic hedgehog leads to morphological changes during fin development. PLoS One 4:e5121.

65. Neumann CJ, H Grandel, W Gaffield, S Schulte-Merker and C Nusslein-Volhard. (1999). Transient establishment of anteroposterior polarity in the zebrafish pectoral fin bud in the absence of sonic hedgehog activity. Development 126:4817-4826.

66. Rodrigues FSLM, G Doughton, B Yang and RN Kelsh. (2012). A novel transgenic line using the Cre-lox system to allow permanent lineage-labeling of the zebrafish neural crest. Genesis 50:750-757.

67. Waxman JS and D Yelon. (2011). Zebrafish retinoic acid receptors function as context-dependent transcriptional activators. Dev Biol 352:128-140.

68. Wang W, J Yang, H Liu, D Lu, X Chen, Z Zenonos, LS Campos, R Rad, G Guo, et al. (2011). Rapid and efficient reprogramming of somatic cells to induced pluripotent stem cells by retinoic acid receptor gamma and liver receptor homolog 1. Proc Natl Acad Sci U S A 108:18283-18288.

Address correspondence to:

Dr. William Eustace Basil Johnson

Life \& Health Sciences Aston University Aston Triangle Birmingham B4 7ET United Kingdom

E-mail: w.e.johnson@aston.ac.uk

Received for publication May 10, 2014 Accepted after revision September 18, 2014 Prepublished on Liebert Instant Online September 18, 2014 